\title{
Winter climate change, plant traits and nutrient and carbon cycling in cold biomes
}

Received: 3 September 2013 / Accepted: 20 November 2013/Published online: 19 December 2013 (C) The Ecological Society of Japan 2013

\begin{abstract}
It is essential that scientists be able to predict how strong climate warming, including profound changes to winter climate, will affect the ecosystem services of alpine, arctic and boreal areas, and how these services are driven by vegetation-soil feedbacks. One fruitful avenue for studying such changing feedbacks is through plant functional traits, as an understanding of these traits may help us to understand and synthesise (1) responses of vegetation (through 'response traits' and 'specific response functions' of each species) to winter climate and (2) the effects of changing vegetation composition (through 'effect traits' and 'specific effect functions' of each species) on soil functions. It is the relative correspondence of variation in response and effect traits that will provide useful data on the impacts of winter climate change on carbon and nutrient cycling processes. Here we discuss several examples of how the trait-based, response-effect framework can help scientists to better understand the effects of winter warming on key ecosystem functions in cold biomes. These examples support the view that measuring species for their response and effect traits, and how these traits are linked across species through correspondence of variation in specific response and effects functions, may be a useful approach for teasing out the contribution of changing vegetation composition to winter warming effects on ecosystem functions. This approach will be particularly useful when linked with ecosystem-level measurements of veg-
\end{abstract}

J. H. C. Cornelissen ( $\square)$

Systems Ecology, Department of Ecological Science, Faculty of Earth and Life Sciences, VU University, De Boelelaan 1085, 1081 HV Amsterdam, The Netherlands

E-mail: j.h.c.cornelissen@vu.nl

K. Makoto

Graduate School of Environment and Information Sciences,

Yokohama National University, Yokohama 240-8501, Japan

Present address:

K. Makoto

Nakagawa Experimental Forest, Field Science Center for Northern Biosphere, Hokkaido University, Otoineppu, Nakagawa, Hokkaido 098-2501, Japan etation and process responses to winter warming along natural gradients, over medium time scales in given sites or in response to experimental climate manipulations.

Keywords Alpine Arctic Biogeochemistry $\cdot$ Boreal Plant functional traits $\cdot$ Response-effect framework · Snow roots $\cdot$ Species ecosystem impact $\cdot$ Winter climate warming

\section{Impacts of winter climate change}

The world's climate is warming rapidly, and the rate of warming is particularly rapid at high latitudes and altitudes, where changes to the winter climate are a paramount component of the overall warming trend (ACIA 2005; IPCC 2007; Wipf and Rixen 2010). These winter changes can be characterised by (1) shifts (often declines) in the amount of snow fall as well as in the duration of snow cover; (2) an increase in the temperature variability and in the frequency of extreme winter warming events; (3) great spatial variability in the direction and dynamics of these changes (ACIA 2005; Callaghan et al. 2011; Johansson et al. 2011; Bokhorst et al. 2012; Makoto et al. 2013). Based on many recent field experimental studies, natural gradient studies and long-term monitoring work, scientists are beginning to get a grip on the direct responses of vegetation to changing winter climate (Wahren et al. 2005; Jonas et al. 2008; Wipf et al. 2009; Wipf and Rixen 2010; Kreyling et al. 2011, 2012), even though in most studies it has been impossible to disentangle winter warming effects from warming effects in the snow melt and growing seasons (but see Dorrepaal et al. 2004; Wahren et al. 2005; Keuper et al. 2011). For example, the much reported expansion of shrubs into many cold climate ecosystems worldwide seems to be due to the combined effects of both winter warming and summer warming. However, neither the effect of winter warming per se, nor its interaction with warming of the summer climate, are well understood (Sturm et al. 2005; Wookey et al. 2009). One aspect that is increasingly 
being recognised is that long-term vegetation responses to (winter) climate warming are the result of the direct and indirect impacts of temperature and precipitation changes - with direct impacts on plant performance and indirect impacts through plant-soil feedbacks (Callaghan et al. 2004; Sturm et al. 2005; Wookey et al. 2009; Chapin et al. 2010; Makoto et al. 2013). These feedbacks are often complex and difficult to unravel because any change in one organism, whether a plant, microbe or animal, may have knock-on effects on both the biotic and abiotic components, which in turn may affect the performance and abundance of the organism itself. In other words, we need to be able to link the responses and effects of different species in cold biome ecosystems that are subject to (winter) climate warming. As the fast rate of climate warming does not allow scientists the time to test each species of each trophic group for its potential responses and ecosystem effects individually, shortcuts based on generalities in organismal functioning must be found. This is where the functional trait concept, and specifically the trait-based 'response and effect framework' (Lavorel and Garnier 2002; Suding et al. 2008; Diaz et al. 2013) may add a novel and particularly useful dimension to winter climate impact research. Below we will first introduce this framework (summarised in Fig. 1), provide some pointers on how it could be applied in various arctic, alpine and boreal contexts and then illustrate the potential power of this approach with empirical examples. The focus of this paper is mostly plant traits, but the framework can also be applied to other organisms (see section Linking response and effect traits: real life examples).

\section{The framework: response and effect traits in a winter climate context}

Within any major group of organisms, species vary greatly in their functional traits, which can be physical, biochemical, physiological, phenological or (in the case of animals) behavioural characteristics that can be measured on (parts of) individuals or populations (Violle et al. 2007). Functional traits have been classified into two major groups: response traits and effect traits (Lavorel and Garnier 2002; Diaz et al. 2013).

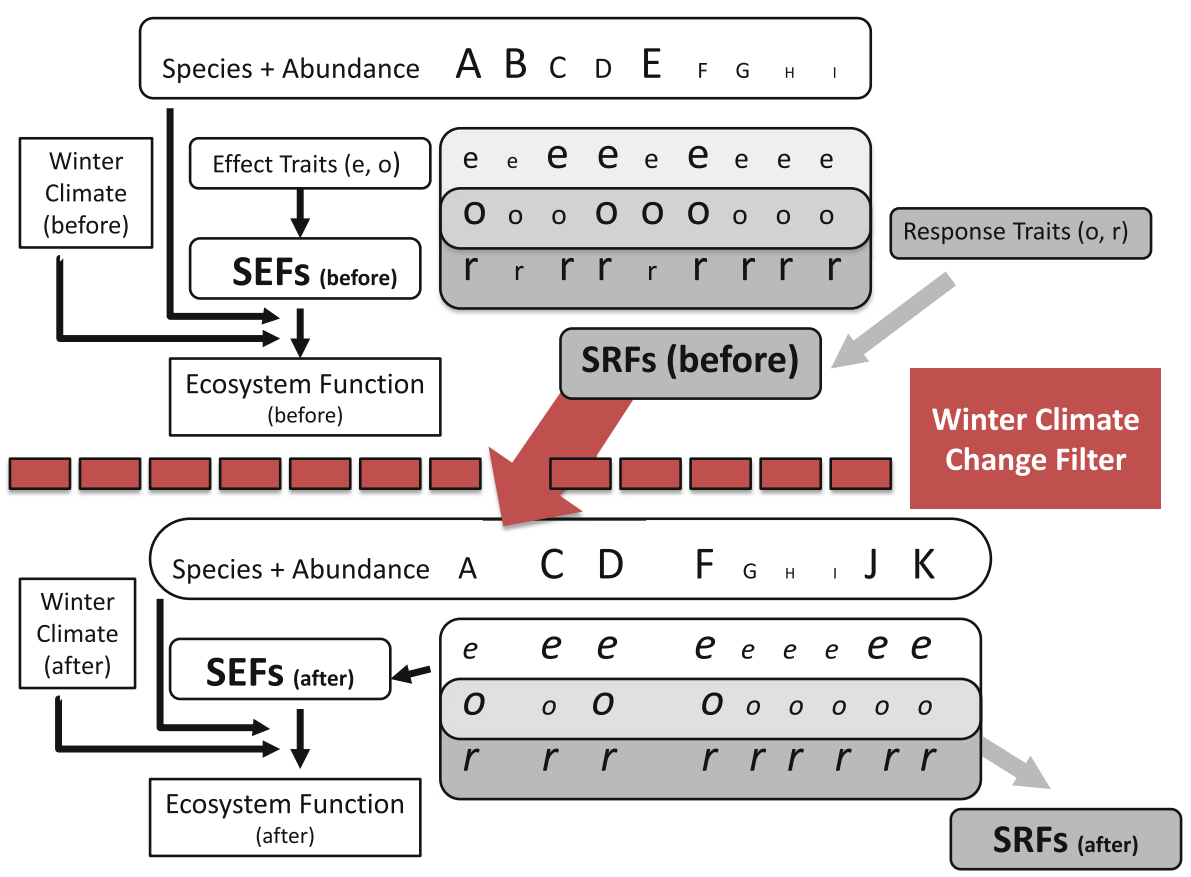

Fig. 1 The response-effect framework and winter climate change. Before winter warming (top half) species $A-I$ vary in abundance, visualised by relative font size. These species have effect traits $e$ and $o$, the values of which are represented by relative font size. Together $e$ and $o$ define a specific effect function ( $S E F$, e.g. litter decomposability). The actual effect of the SEFs on the ecosystem function (e.g. decomposition rate) is modulated by the species' abundances and direct abiotic effects of winter climate on the ecosystem function (top left hand corner). The same species also have response traits $r$ and $o$ (the latter also being an effect trait), the values of which are represented by relative font size. Together these response traits define the specific response functions $(S R F)$ of species $A-I$. The values for these SRFs (e.g. heat tolerance) determine which of the species pass the filter imposed by winter climate change (central dashed line). Species $B$ and $E$, which had low values for the SRF, are filtered out, while two new species $J$ and $K$ establish in the ecosystem. Note that not only the species composition but also their abundances have changed. The response and effect traits, as well as SRFs and SEFs, are broadly the same as before for a given species, but they may have changed somewhat (indicated by italics) owing to phenotypic response or genotypic change. The ecosystem function will now have changed as a dependent variable on the new species abundances and their SEFs and any direct (abiotic) effects of winter climate change on the function (bottom left hand corner) 
Response traits and specific response functions

Response traits are those traits that can be clearly associated with the fitness of the species in a certain environment and therefore may also affect its performance when this environment changes. The usual approach is to test a range of species in a standardised way (Pérez-Harguindeguy et al. 2013) in order to rank the value or category for a certain response trait relative to those of other species in the same ecosystem or region (Fig. 1). There are many examples of response traits that may be relevant to winter climate and which can be measured on multiple species in a given environment. The first of these is leaf nitrogen $(\mathrm{N})$ concentration, an important element in the enzyme Rubisco that supports the photosynthetic production and thereby plant growth. In addition, $\mathrm{N}$ may be an important component of glycol-like anti-freeze compounds in the tissues. Second, for snow bed species, which only have a short growing season after snow melt to complete their entire annual cycle, interspecific variation in leaf and reproductive phenology is also known to be important (Kudo et al. 1999; Aerts et al. 2004; Kawai and Kudo 2011). Phenological traits tend to be both species specific and phenotypically plastic; for example, flowering phenology varies among species and (for given species) is responsive to winter and spring temperature regimes in subarctic peat bogs (Aerts et al. 2004). Such differences between species' phenologies, both overall and in their response to temperature, may be a key factor in their long-term reproductive success, thereby filtering out certain species and letting new ones establish in a cold ecosystem subject to winter warming (Fig. 1). As a third example, growth form (Pérez-Harguindeguy et al. 2013) is a response trait known to be important for survival in cold and dry alpine and arctic sites. An example of this is the cushion growth form, which helps a plant to warm up and become photosynthetically active faster after snow melt and to maintain warmer temperatures, even more so if it associated with a dark leaf colour (e.g. in Diapensia lapponica) promoting absorption of solar radiation (Körner 2003).

However, it is important to realise that the response of a species in a given ecosystem subject to winter climate change will not necessarily depend on merely one response trait. Often several response traits together will determine the potential response of a species to winter climate, and this potential response has recently been proposed as the 'specific response function' (SRF) (Diaz et al. 2013; see Fig. 1). Obvious examples of key SRFs in our winter climate context are heat tolerance (Fig. 2) and cold tolerance. Leaf frost (or cold) tolerance, for instance, may depend on a combination of several underlying anatomical, physiological and biochemical response traits, such as specific leaf area (SLA) (Hekneby et al. 2006), vessel morphology (Hacke et al. 2007), cuticle thickness (Wang et al. 2008), solute transport physiology and concentrations of anti-freeze compounds (e.g. glycols and soluble sugars) (Kasuga et al. 2007,
2008). Depending on the questions asked and the facilities and expertise at hand, species can be screened for the underlying traits (thereby providing a better mechanistic understanding of variation in frost tolerance), or they can be screened for frost or cold tolerance in a relatively 'quick and dirty' direct way, such as through a standardised electrolyte leaching assay (Pérez-Harguindeguy et al. 2013). Frost tolerance of reproductive plant parts (SRF) in the cold biome of temperate mountains has been attributed to a combination of underlying response traits, including physiological traits, (cushion) growth form and plant height, where low stature (to keep reproductive parts below snow cover) may in fact be a frost avoidance mechanism (Ladinig et al. 2013). For a given aspect of winter climate change in a given site or ecosystem, such as shortening of the season of snow cover, the relevant SRFs of the respective species will determine which species can pass through the climate change filter (sensu Diaz et al. 1998) successfully and perhaps even increase in abundance (e.g. species $\mathrm{F}$ in Fig. 1) and which species will decrease (e.g. species A) or even disappear from the system (e.g. species B). Moreover, new species from the regional species pool ( $\mathrm{J}$ and $\mathrm{K}$ in Fig. 1), with the right SRF makeup, may arrive, establish and soon become important members of the community. An important addition to the concept is that biotic interactions are also important (see also section Research agenda), including competitive and facilitative interactions. Consequently, the abundance of those species that have passed the winter climate change filter successfully will also depend, for example, on competitive strength, for which other response traits (e.g. leaf $\mathrm{N}$, canopy height, woodiness, nutrient uptake strategy; see below) will be important.

\section{Effect traits and specific effect functions}

The crux of the framework is that the response of key ecosystem functions to winter climate change through changes in species composition not only depends on the response traits and SRFs of the species, but also on how variation in response traits among species lines up (or not) with variation in their effect traits (Fig. 1). Effect traits are those traits which underpin important effects a species can have on ecosystem functions of interest. In the context of carbon (C) and nutrient cycling these functions include, for example, litter decomposition rates (to maintain soil fertility) or food supply (e.g. tundra lichens) to certain animals (e.g. reindeer). More specifically, leaf tannin concentration will reduce the palatability and digestibility of the leaf to herbivores, but will also slow down litter decomposition rates (Coley 1988; Hattenschwiler and Vitousek 2000; Cornelissen et al. 2004), thereby having a negative overall effect on $C$ and nutrient cycling. However, as with response traits, often several underlying effects traits will together determine the potential effect an individual or a unit of biomass of a species has on an ecosystem function. This 

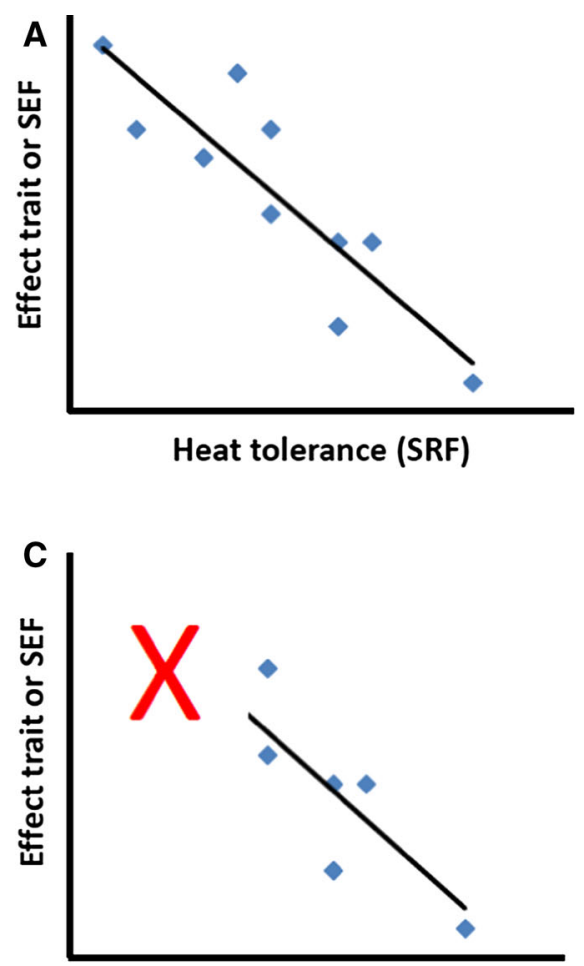

Heat tolerance (SRF)

Fig. 2 Hypothetical figures (based on Suding et al. 2008; Diaz et al. 2013) depicting the correlation between a SRF, such as heat tolerance here, and an effect trait or SEF (e.g. litter decomposability). a Strong negative correlation between SRF and SEF. b No correlation between SRF and SEF. c Winter warming eradicates ('crosses out') the top left half of the species in a, i.e. those with low heat tolerance. The remaining species on average have low values

potential effect has recently been proposed as the 'specific effect function' (SEF; Diaz et al. 2013). For example, a species' leaf litter quality to decomposers will depend on a combination of chemical and physical defences and on the nutrients that will still be present in the leaf after senescence (Cornelissen et al. 2004).

A good illustration of an SEF and its underlying effect traits of particular relevance to winter climate warming comes from the subalpine grasslands in the French Alps. On mountain slopes where traditional land use (especially mowing and fertilising) has been abandoned, the grass Festuca paniculata tends to expand and develop virtual monocultures. It has a tussock growth form with particularly tough leaves (of low SLA) with a smooth surface (three response traits) compared to other species in this subalpine belt (Quetier et al. 2007). The tussocks die back and bend over in autumn but barely decompose (as related to high leaf toughness), thereby creating a persistent, very smooth-surfaced dead leaf canopy. In winter, when snow covers the landscape, this slippery canopy is an unstable support for the snow cover (SEF) and seems to increase the risk of avalanches (Quetier et al. 2007), thereby providing a positive feedback to the growing climate-induced risk of avalanches in this region. This is captured in Fig. 1 (bottom left
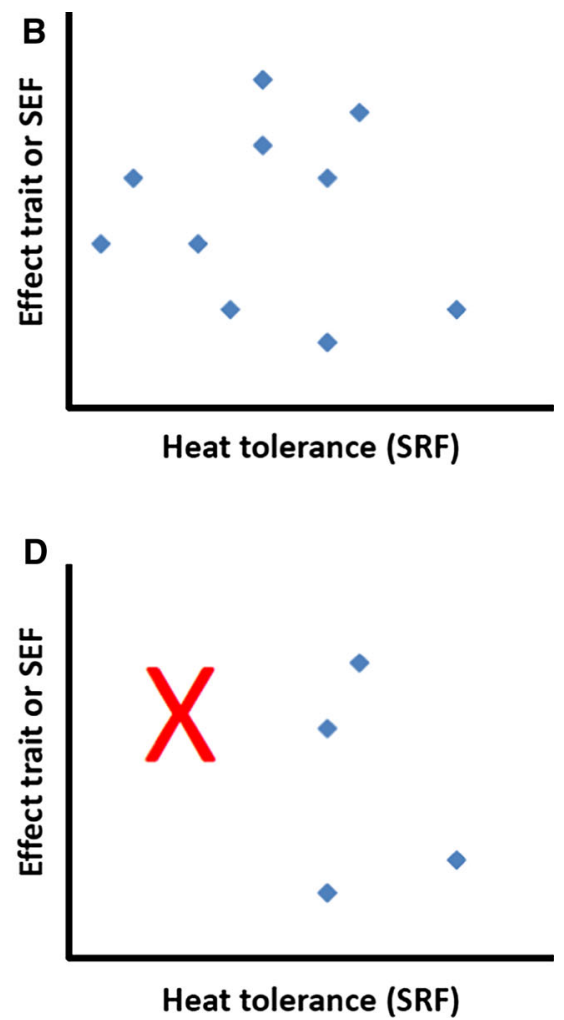

for the SEF (e.g. litter decomposability), so the likely effect on the ecosystem function (e.g. decomposition) is large. d Again, the species in $\mathbf{b}$ with low heat tolerance are eradicated ('crossed out') by winter warming, but here the remaining species show both high and low values for the SEF, so the ecosystem function is unlikely to change drastically based on species effects

corner) by the interaction of a direct effect and an SEFmediated effect of winter climate warming on an ecosystem function - in this case, protection of snow cover (and its knock-on effects on vegetation cover and thus the $\mathrm{C}$ and nutrient cycles).

Bryophytes provide further examples of SEFs that underpin likely changes in ecosystem processes and services under changing winter climate change scenarios. They are well known as paramount ecosystem engineers in cool and cold biomes (Longton 1997; Street et al. 2013), and these engineering functions vary greatly among species as a result of interspecific variation in SEFs and the underlying effect traits (Cornelissen et al. 2007b). For example, Lang et al. (2009) compared 27 different subarctic moss and liverwort species (and several vascular species as a reference) for their litter decomposability (SEF) by incubating them all simultaneously in litterbags in a standard moss-rich environment ('litter bed'). While virtually all bryophyte species decomposed much slower than any vascular plant litter, there was also striking variation in decomposability among bryophyte species, with Sphagnum generally being very recalcitrant to decomposition compared to other bryophytes. This underpins the role of Sphagnum as the number one $\mathrm{C}$ accumulator worldwide (Gorham 
1991). There was also great variation in decomposability between non-Sphagnum bryophytes as well as between Sphagnum species. This interspecific variation in decomposability could be underpinned with several chemical effect traits, including secondary compounds (Lang et al. 2009). These findings are very relevant where and when (winter) climate warming causes shifts in the relative abundances of bryophytes versus vascular plants, of Sphagnum versus non-Sphagnum bryophytes or within (non-)Sphagnum bryophytes. Based on the variation in decomposability as an SEF, great shifts in ecosystem level decomposition and nutrient dynamics are to be expected in bryophyte-rich systems in such scenarios.

Bryophytes are also ecosystem engineers through their control on soil hydrology and temperature regimes, by buffering against abiotic extremes and thereby protecting the soil against permafrost thaw (Gornall et al. 2007; Blok et al. 2011a) and the associated mineralisation of carbon and nutrients stored in peat layers. However, only recently has it been shown that these potential effects of cold biome bryophytes on soil moisture and temperature regimes (i.e. SEFs) can vary greatly among species (Elumeeva et al. 2011; Michel et al. 2012). Soudzilovskaia et al. (2013) have recently provided a nice example of this in the context of winter climate change. These authors demonstrated experimentally how natural mats of 17 different bryophyte species in subarctic Sweden all buffered the amplitudes of soil temperatures below them and that they strongly reduced the frequency of freeze-thaw events - which are especially predominant at the end of winter and in spring. This is very important for the fate of the $\mathrm{C}$ and nutrients stored in the soils below these bryophytes. Moreover, large differences among species in terms of their potential effect on temperature regime (SEF) were found, which could be explained fully by the mat thickness and moisture content as underlying effect traits-although mat moisture content in this study was presumably due to both water holding capacity, the actual effect trait and field moisture conditions.

Figure 1 also illustrates that the winter climate (change) filter not only affects species composition before versus after it, but also the abundance distribution of the species. According to the 'mass ratio hypothesis' (Grime 1998), the effect a species has on its ecosystem is proportional to its abundance or biomass, and this is likely largely to be true for many ecosystem functions related to $\mathrm{C}$ and nutrient cycling. Therefore, the overall effect the plant community has on an ecosystem function should be the integrated result of (1) the SEFs of the most important set of species, (2) multiplied by their abundances and (3) any direct (abiotic) effect on the ecosystem function. Again, biotic interactions, including non-additive diversity effects and trophic cascades of connected response and effect traits (Krab 2013), may also be important drivers, but this aspect will only be briefly discussed (see section Research agenda).
Linking response and effect traits: real life examples

It is also possible that a trait is both response and effect trait (see trait 'o' in Fig. 1). Leaf $\mathrm{N}$ concentration is an obvious plant example of a twin response-effect trait (Diaz et al. 2013; see also sections Response traits and specific response functions and The framework applied to snowbed communities: snow roots and nutrient cycling).

Regarding animals, the body sizes and associated behavioural traits of a range of vertebrate tundra herbivores can be both response and effect traits. On the one hand they will determine snow-related SRFs, for example, whether they need to spend the winter underneath a protective snow pack (e.g. voles, lemmings) or whether they are sufficiently cold tolerant to remain on top of the snow during cold winter periods (e.g. moose, reindeer). At the same time, also related to body size, the small rodents will mostly eat stems and leaves of small dwarf shrubs and herbaceous plants below the snow, while moose browse branches of shrubs and trees sticking out above the snow and reindeer forage specifically for lichens below the snow. Through this variation in the twin response-effect traits these animals will respond differently to changes in snow cover and have very different potential effects (SEF) on the $\mathrm{C}$ and nutrient turnover of the vegetation.

It is the correlation between interspecific variation in response traits and that in effect traits, and especially the correlation between interspecific variation in an SRF and an SEF, that provides us with valuable data on the potential for change in a certain ecosystem function, as well as its magnitude (Suding et al. 2008; Diaz et al. 2013). This is illustrated in the imaginary example in Fig. 2, with heat tolerance as the SRF plotted against a hypothetical effect trait or SEF (e.g. leaf litter decomposability). In the case of a heat wave, a strong correlation between SRF and effect (Fig. 2a) would likely lead to a large change in the ecosystem function (reduced process rate in this example) because the heat-intolerant species with high values for the SEF would be eliminated from the ecosystem (Fig. 2c). In contrast, decoupling of the SRF and the effect (Fig. 2b) would be unlikely to lead to a drastic change in the ecosystem function, as both low and low values would still be represented in the community (Fig. 2d). Note that this imaginary example does not take into account the establishment of possible new species with effect traits that may or not be different from those of the species already present (Fig. 1).

For a first qualitative illustration of this principle let us draw from the 'hot' issue of the recent shrub expansion into tundra at high latitudes and altitudes in response to climate warming (Elmendorf et al. 2012). This is a very complex issue involving multiple interacting feedbacks relating to both summer and winter processes (Sturm et al. 2005; Wookey et al. 2009). Tundra shrubs have a set of response traits that enable them to benefit from climate warming and the associated enhanced soil nutrient mineralisation rates. These response traits 
include (1) woodiness, enabling them to invest photosynthates into (2) relatively tall and persistent structures with broad canopies, which protrude above the snow and thereby enable (3) early leaf bud burst. This early leaf phenology helps the shrubs to exploit the spring nutrient flush around snow melt to enhance spring growth and shade the smaller herbaceous plants. Together these response traits lead to a relatively high growth responsiveness to winter warming (SRF). In this case, plant height and canopy width are not only response traits but also effect traits. One important aspect of the winter climate feedback is that, at a given annual snow input regime to a tundra system, the taller shrubs tend to trap more snow than their herbaceous neighbours. Snow capture capacity can be considered as a SEF because the plant-mediated increase in depth of the insulating snow cover enhances winter soil temperatures and, subsequently, nutrient mineralisation rates in spring (Schimel et al. 2004; Sturm et al. 2005; Wookey et al. 2009; Rogers et al. 2011). This leads to a positive feedback to the stimulation of shrub growth in response to summer warming. However, the story is more complex, as shrub expansion has several other effects on the tundra ecosystem both above- and belowground (reviewed by Wookey et al. 2009). One of those effects involves litter feedback. In a large field experiment, Cornelissen et al. (2007a) collected leaf litter of different herbaceous functional types and shrubs from multiple species and tundra sites all over the world and incubated all of these litter types at both a low and high altitude in subarctic Sweden. These authors found not only an obvious and strong direct positive effect of higher temperatures on litter decomposition rates of all functional types, but also observed that shrub litter (both deciduous and evergreen) was generally decomposed substantially slower than herbaceous litter at a given climatic regime owing to their generally high values for the effect traits lignin/ $\mathrm{N}$ ratio and phenol/ $\mathrm{N}$ ratio (Cornelissen et al. 2004). This difference in leaf litter decomposability (SEF) was of a similar magnitude as the difference due to incubation climate. These findings led the authors to suggest that the lower decomposability of the shrubs is likely to provide strong negative feedback to tundra litter decomposition and nutrient mineralisation, taking away some of the positive feedback of higher temperatures to shrub expansion (Cornelissen et al. 2007a). The tundra climate warming-vegetation feedbacks are still much more complex than each of its components (Wookey et al. 2009; Blok et al. 2011b; Elmendorf et al. 2012). However, these selected components serve to illustrate that framing these complex feedbacks in terms of response and effect functions, and their underlying response and effect traits, can help scientists unravel these feedbacks in a structured way.

Lichens are another group of organisms for which the trait-based response-effect framework may facilitate an understanding of the impacts of winter climate change. Cold biome lichens are known to be extremely cold tolerant compared to most vascular plants, partly due to their poikilohydric physiology (response trait), and they also show great interspecific variation in cold tolerance (SRF) (Kappen 1993, 2000; Insarova and Insarova 1996). Moreover, several species are known to be able to photosynthesize substantially at sub-zero temperatures when still covered by snow by using snow or ice as a water source, and this ability (SRF) also varies among lichen species (Kappen 1993; Kappen et al. 1995). Compared to vascular plants, lichens are also particularly tolerant of soil perturbation caused by frost-heave in tundra polygons (SRF) (Jonasson and Sköld 1983; Jonasson and Callaghan 1992; Makoto and Klaminder 2012) due to their lack of roots (response trait), which might get killed during frost-heave, as is the case in vascular plants. It is not yet precisely clear how different lichen species might differ in their tolerance of frost heave - especially in their relative ability to exploit the open, often more base and nutrient-rich patches it creates and the subsequent succession of these patches (but see Jonasson and Sköld 1983; Makoto and Klaminder 2012). At the same time, lichen species vary greatly in several key SEFs. Firstly, several taxa feature symbioses with $\mathrm{N}_{2}$-fixing cyanobacteria (Palmqvist 1995) and thereby contribute importantly to the natural $\mathrm{N}$ inputs into boreal forest and arctic tundra, which tend to be strongly N-limited in their productivity (Crittenden and Kershaw 1978). This $\mathrm{N}_{2}$-fixing capacity (SEF) also varies greatly among N-fixing species (Nash 1996; Gavazov et al. 2010). Lichens are also an important food source to reindeer (caribou), especially in winter, when these animals depend on lichens for their high caloric (carbohydrate) content. The quality of lichens as a food source for reindeer is an SEF that depends both on growth form (order of preference: fruticose $>$ foliose $>$ crustose form) and on biochemical traits (Danell et al. 1994). As cold biome lichen biodiversity and abundance, and the ecosystem services they provide, are under severe pressure from (direct and indirect effects of) climate warming and overgrazing (Cornelissen et al. 2001), it would be highly relevant to study the extent to which interspecific variation in the above (and other) SRFs related to winter climate response corresponds with that in the lichen SEFs mentioned.

\section{The framework applied to snowbed communities: snow roots and nutrient cycling}

Now let us apply the response-effect framework to winter climate and nutrient cycling in snow bed plant communities. Snow beds are known for their high and special biodiversity, the alpine ecosystem services they provide and their vulnerability to climate warming (Björk and Molau 2007). The Russian Caucasus Mountains host especially interesting alpine snow beds, the productivity of which has been shown to be colimited by phosphorus (P) and $\mathrm{N}$ (Onipchenko et al. 2012). Onipchenko et al. (2009) recently discovered a previously overlooked nutrient uptake strategy in these 
snow beds. These authors found that the endemic snow bed specialist Corydalis conorhiza, a member of the Papaveraceae family, not only develops regular roots in the soil, which are infected with arbuscular mycorrhizal fungi presumably to promote its $\mathrm{P}$ uptake from the soil but that in winter it also develops 'snow roots', which are specialised 'throw-away' roots that have obviously evolved to scavenge for nutrients, especially $\mathrm{N}$, in the snow. These latter roots start to grow relatively early in the winter from belowground reserves and grow against gravity up into the snow pack (Onipchenko et al. 2013). The snow roots develop dense networks in the snow, which at the end of the early summer thaw can be found as a striking white root mat on the surface of the ground,

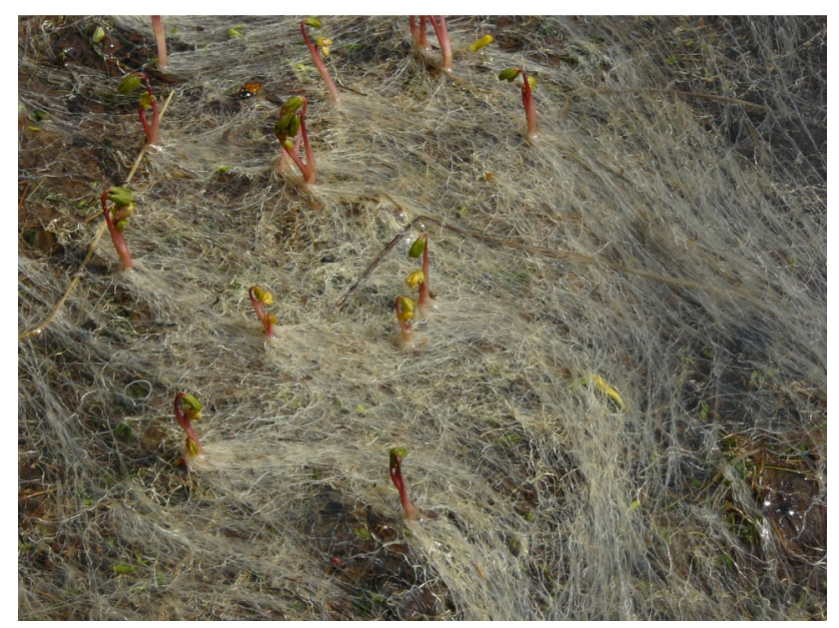

Fig. 3 Shoots of Corydalis conorhiza pushing through a dense network of its own snow roots; these snow roots have come to rest on the soil surface as a consequence of the melting snow pack. Photo was taken on Mt. Khatipara in the Russian Caucasus Mountains by V.G. Onipchenko left behind by the melting snow. At that time the new shoots emerge and push up through the snow roots (Fig. 3). By labelling snow packs with the stable isotope ${ }^{15} \mathrm{~N}$, Onipchenko et al. (2009) revealed that these snow roots are both efficient at taking up $\mathrm{N}$ from the snow packs and at translocating this $\mathrm{N}$ to the other plant organs, including the leaves. This newly described $\mathrm{N}$ uptake strategy helps $C$. conorhiza to match $\mathrm{P}$ uptake through its mycorrhizal soil-based roots with substantial $\mathrm{N}$ uptake in these $\mathrm{N}$ and $\mathrm{P}$ co-limited snow beds. In other words, this strategy helps the species to make a living in response to long-persisting snow cover (SRF). In this study, some key underlying response traits of $C$. conorhiza and its neighbours were also quantified. Firstly, Onipchenko et al. (2009) showed that in several anatomical traits the snow roots were fundamentally different from normal soil-dwelling roots; they were long and very thin, without an obvious protective epidermis but with a conspicuous endodermis, presumably designed to actively load $\mathrm{N}$ into the xylem for translocation to other plant organs. The visually small investments in structure relative to length were confirmed by comparing the specific root length (SRL; length per dry mass) of the snow roots with those of soil-dwelling roots, with the SRL being a key response trait associated with the efficiency of water and nutrient uptake (PérezHarguindeguy et al. 2013). Onipchenko et al. (2009) showed that the SRL of snow roots was not only fivefold greater than that of the soil-dwelling roots of C. conorhiza, but also five-fold greater than (and outside the upper range of) the SRL of 99 (mostly herbaceous) species in the same alpine belt at the same site (Fig. 4a). Together, the results for these anatomical and structural response traits strongly underpin the $\mathrm{N}$ uptake function of the snow roots, as well as the competitiveness of $C$. conorhiza in this harsh late-melt snow bed environment.
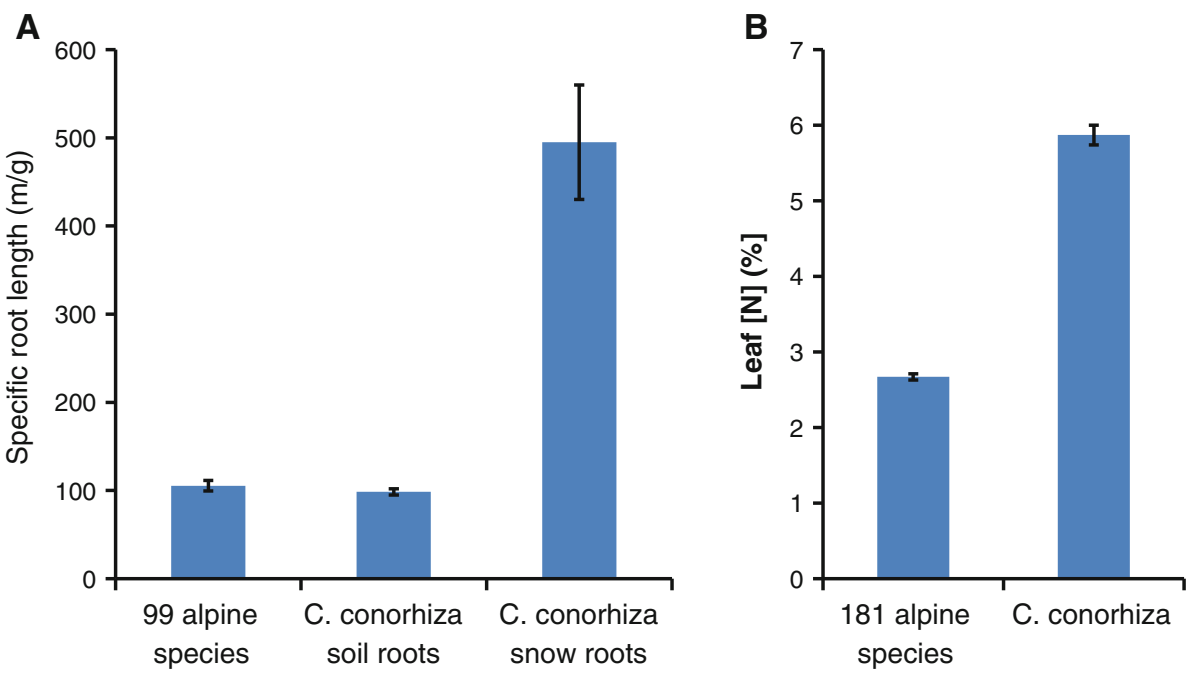

Fig. 4 a Specific root length in C. conorhiza snow roots versus its own soil-dwelling roots and those of neighbour species in the same alpine site on Mt. Khatipara in the Russian Caucasus Mountains. b Leaf nitrogen concentration ([N]) of C. conorhiza compared to that of neighbour species in the same alpine site 
Do the snow roots also relate to specific effect functions of $C$. conorhiza relative to those of other species in this alpine belt? We believe they do, based again on trait measurements. First, much of the snow-melt water and the nutrients it contains may run down the mountain slope over a surface ice crust, so the snow roots capture part of the $\mathrm{N}$ that would otherwise be lost to the snow bed community. These snow roots themselves are decomposed within the same growing season (Onipchenko et al. 2013), thereby presumably 'donating' its nutrients to the ecosystem. Moreover, the leaves of $C$. conorhiza turned out to support the highest $\mathrm{N}$ concentrations of any of the 181 other species in the same alpine belt, and more than twice higher than their average (Onipchenko et al. 2009; Fig. 4b). Also, the SLA of $C$. conorhiza was $25 \mathrm{~mm}^{2} / \mathrm{mg}$, which was high compared to the mean of $204 \pm 7$ for 171 other species in the same alpine belt (VG Onipchenko, NA Soudzilovskaia and JHC Cornelissen, unpublished data). High leaf $\mathrm{N}$ and high SLA (i.e. low leaf mass per area; little structural investment) are generally associated with fast leaf litter decomposition (Cornelissen and Thompson 1997; Cornwell et al. 2008). This notion was confirmed by a combination of empirical and visual observations. A litterbed study with simultaneous and in situ incubation of leaf litters of 18 alpine species from this site showed that, on average, mass loss was just over $50 \%$ over 1 year (Freschet et al. 2013), while leaf litter of C. conorhiza is already virtually invisible by the end of the growing season in which they emerge, i.e. within 2 months (V.G. Onipchenko, personal observations). The high decomposability (SEF) and fast turnover of $C$. conorhiza litter compared to that of other species in this belt may have ecosystem-level consequences. It is likely that a substantial portion of the $\mathrm{N}$ captured by the snow roots will benefit other (plant) species in the same snow bed community due to the fast turnover of its N-rich (root and) leaf litter.

However, it is not hard to imagine that this recently discovered 'new cog' in the $\mathrm{N}$ cycle of Caucasian snow beds is very vulnerable to winter climate warming. We hypothesise that its dependence on snow roots also makes $C$. conorhiza particularly intolerant of reduced snow cover, in which case it might lose its competitive advantage compared to other snow bed species. If it turns out it will not be able to pass the filter (Fig. 1) of winter climate warming, which is currently happening in the Caucasus as evidenced by the fast retreat of glaciers, this would have possible knock-on effects on $\mathrm{N}$ availability and related functions in this precious ecosystem.

\section{Research agenda}

In writing this review we had two main aims. First, we hope that this review would function as an invitation to intensify ecological research on winter climate change effects on ecosystem functions, thereby addressing one of the key issues of environmental concern this century.
Secondly, we also hope to provide an impetus to such research by linking functional trait information of the plant community and information on the associated plant-soil feedbacks through the response-effect framework set out here and illustrated with preliminary real-life examples. These examples together support the usefulness of measuring response and effect traits, and/ or SRFs and SEFs, for the predominant members of plant communities. We believe that the trait-based response-effect framework as presented here in the winter climate change context will be especially useful for deriving and underpinning predictions about winter warming impacts on ecosystem functions.

However, this approach will be especially useful if it is complemented by other approaches. Such approaches include measuring species presence and abundance (see Fig. 1, abundance represented by font size of species codes) and ecosystem properties in response to changing winter climate (1) along natural climatic gradients, (2) over time in given environments, (3) in field manipulation experiments or (4) by modeling - or better still by a combination of such approaches (Callaghan et al. 2004). These approaches comprise not only trait-mediated effects, but also direct, abiotic winter warming effects on ecosystem functions (Fig. 1, left-hand boxes), even though they cannot easily unravel the effects of biotic and abiotic drivers. We know, for example, that litter decomposition, the biotic control of which has been emphasised in this review, is also under strong direct climatic control, with a key role for winter climate (Hobbie and Chapin 1996; Baptist et al. 2010; Wu et al. 2010).

In terms of field manipulation experiments, we advocate not limiting our focus to only experiments specifically targeting the winter climate (e.g. snow removal, snow accumulation through snow fences, active continuous or pulse-wise winter warming), however useful these have already been proven to be. Factorial designs with warming treatments in different seasons of the year, both winter and non-winter, will yield additional insights that cannot be gained from winter climate manipulations alone because winter and summer warming will influence one another through, for example, changing species composition, seasonal microbial communities, memory effects of winter damage on summer productivity, late summer weather affecting the intensity of soil frost before snow cover, among others. For such interactions (summer responses having subsequent winter effects and vice versa) the response-effect framework may be particularly useful. A long-term field manipulation experiment with factorial winter and non-winter treatments in a peatbog in subarctic Sweden exemplifies the promise of such combined seasonal climate manipulations (Dorrepaal et al. 2004; Aerts et al. 2012).

Gradient (1), monitoring (2) experimental (3) and modeling approaches (4) will enable scientists to incorporate two further aspects of the complexity of winter warming effects on ecosystem function via species traits. First, while in this review we have focused on 
interspecific variation, we should by no means neglect the importance of intraspecific trait variation (Albert et al. 2011). There are several reports of intraspecific variation that are relevant to winter climate. For example, increased leaf $\mathrm{N}$ concentration in response to deeper snow cover has been reported for tundra graminoids and shrubs (Walsh et al. 1997; Torp et al. 2010, Rogers et al. 2011), although not in a subarctic peatbog (Aerts et al. 2007). Moreover, foliar concentrations of several phenolic compounds of subarctic dwarf birches (Betula nana) have been observed to change with experimentally increased snow cover (Torp et al. 2010); together with increased leaf $\mathrm{N}$ concentration this response resulted in greater palatability of the leaves to autumn moth caterpillars (Epirrita autumnata). In this case leaf $\mathrm{N}$ concentration and leaf phenolics can be considered both response traits - as they responded to snow cover change - and effect traits - as they supported leaf palatability as a specific effect function, with consequences for ecosystem-scale herbivory. Correspondingly, Mårell et al. (2006) found variation in several effect traits related to leaf and shoot quality of four subarctic species along natural gradients of snow regimes, with consequences for their forage quality to reindeer (SEF). Intraspecific variation in several response traits, including leaf phenology, reproductive phenology, leaf mass per area, leaf lifespan and again leaf $\mathrm{N}$ concentration has been reported as being responsive to snow melt-out time or spring warming along natural gradients and in manipulation experiments (Kudo et al. 1999; Starr et al. 2000; Aerts et al. 2004).

Finally, the above examples indicate that trophic interactions can be important in a winter warming context, as may other types of biotic interactions, such as competition, facilitation, pollination, seed dispersal, microbial and detritivore interactions and diversity effects - to name but a few. Here, also, recent conceptual advances through the response-effect framework may be of great interest, with variation in effect traits at one trophic level linking to variation in response traits at the next trophic level, and so on (Ibanez et al. 2013; Krab 2013).

\section{Conclusion}

In this review we have shown that qualifying and measuring species for their variation in response and effect traits and then studying how these are linked through correspondence of variation in specific response and effects functions may be a useful approach for teasing out the contribution of changing vegetation composition to winter climate warming effects on ecosystem functions. This approach will be particularly useful when linked with ecosystem level measurements of vegetation and process responses to winter warming along natural gradients, over medium time scales in given sites or in response to experimental climate manipulations.
Acknowledgments We gratefully acknowledge the organisers and funding bodies of the 2013 Annual Meeting of the Ecological Society of Japan, in Shizuoka for facilitating the special symposium on Winter Climate Change Effects; and to Professor N. Kachi and Ecological Research for inviting and funding JHCC to join the symposium there. V.V. Onipchenko kindly provided the photo in Fig. 3 and played a leading role in the snow root project. We also acknowledge the moral support of the Kyoto Pagoda Marathon.

\section{References}

ACIA (2005) Arctic climate impact assessment, 2005. Cambridge University Press, Cambridge

Aerts R, Cornelissen JHC, Dorrepaal E, van Logtestijn RSP, Callaghan TV (2004) Effects of experimentally imposed climate scenarios on flowering phenology and flower production of subarctic bog species. Glob Change Biol 10:1599-1609

Aerts R, Cornelissen JHC, van Logtestijn RSP, Callaghan TV (2007) Climate change has only a minor impact on nutrient resorption processes in a high-latitude peatland. Oecologia 151:132-139

Aerts R, Callaghan TV, Dorrepaal E, van Logtestijn RSP, Cornelissen JHC (2012) Seasonal climate manipulations have only minor effects on litter decomposition rates and $\mathrm{N}$ dynamics but strong effects on litter $\mathrm{P}$ dynamics of sub-arctic bog species. Oecologia 170:809-819

Albert CH, de Bello F, Boulangeat I, Pellet G, Lavorel S, Thuiller W (2011) On the importance of intraspecific variability for the quantification of functional diversity. Oikos 121:116-126

Baptist F, Yoccoz NG, Choler P (2010) Direct and indirect control by snow cover over decomposition in alpine tundra along a snowmelt gradient. Plant Soil 328:397-410

Björk RG, Molau U (2007) Ecology of alpine snowbeds and the impact of global change. Arct Antarct Alp Res 39:34-43

Blok D, Heijmans MMPD, Schaepman-Strub G, van Ruijven J, Paramentier FJW, Maxomov TC, Berendse F (2011a) The cooling capacity of mosses: controls on water and energy fluxes in a Siberian tundra site. Ecosystems 14:1055-1065

Blok D, Schaepman-Strub G, Bartholomeus H, Heijmans MMPD, Maxomov TC, Berendse F (2011b) The response of arctic vegetation to the summer climate: relation between shrub cover, NDVI, surface albedo and temperature. Environ Res Lett 6:035502

Bokhorst S, Bjerke JW, Tommervik H, Preece C, Phoenix GK (2012) Ecosystem response to climatic change: the importance of the cold season. Ambio 41:246-255

Callaghan TV, Björn LO, Chernov Y, Chapin T, Christensen TR, Huntley B, Ims RA, Johansson M, Jolly D, Jonasson S, Matveyeva N, Panikov N, Oechel W, Shaver G (2004) Effects on the function of arctic ecosystems in the short- and long-term perspectives. Ambio 33:448-458

Callaghan TV, Johansson M, Brown RD, Groisman PY, Labba N, Radionov V, Barry RG, Bulygina ON, Essery RLH, Frolov DM, Golubev VN, Grenfell TC, Petrushina MN, Razuvaev VN, Robinson DA, Romanov P, Shindell D, Shmakin AB, Sokratov SA, Warren S, Yang D (2011) The changing face of arctic snow cover: a synthesis of observed and projected changes. Ambio 40:17-31

Chapin FS III, McGuire AD, Ruess RW, Hollingsworth TN, Mack MC, Johnstone JF, Kasischke ES, Euskirchen ES, Jones JB, Jorgenson MT, Kielland K, Kofinas GP, Turetsky MR, Yarie J, Lloyd AH, Taylor DL (2010) Resilience of Alaska's boreal forest to climatic change. Can J For Res 40:1360-1370

Coley PD (1988) Effects of plant growth and leaf lifetime on the amount and type of anti-herbivore defense. Oecologia 74:531-536

Cornelissen JHC, Thompson K (1997) Functional leaf attributes predict litter decomposition rate in herbaceous plants. New Phytol 135:109-114 
Cornelissen JHC, Callaghan TV, Alatalo JM, Michelsen A, Graglia E et al (2001) Global change and arctic ecosystems: is lichen decline a function of increases in vascular plant biomass? J Ecol 89:984-994

Cornelissen JHC, Quested HM, Gwynn-Jones D, van Logtestijn RSP, de Beus MAH et al (2004) Leaf digestibility and litter decomposability are related in a wide range of subarctic plant species and types. Funct Ecol 18:779-786

Cornelissen JHC, van Bodegom PM, Aerts R, Callaghan TV, van Logtestijn RSP et al (2007a) Global negative feedback to climate warming responses of leaf litter decomposition rates in cold biomes. Ecol Lett 10:619-627

Cornelissen JHC, Lang SI, Soudzilovskaia NA, During HJ (2007b) Comparative cryptogam ecology: a review of bryophyte and lichen traits that drive biogeochemistry. Ann Bot 99:987-1001

Cornwell WK, Cornelissen JHC, Amatangelo K, Dorrepaal E, Eviner VT et al (2008) Plant species traits are the predominant control on litter decomposition rates within biomes worldwide. Ecol Lett 11:1065-1071

Crittenden PD, Kershaw KA (1978) Discovering role of lichens in nitrogen cycle in boreal-arctic ecosystems. Bryologist 81:258-267

Danell K, Utsi PM, Palo RT, Eriksson O (1994) Food plant selection by reindeer during winter in relation to plant quality. Ecography 17:153-158

Diaz S, Cabido M, Casanoves F (1998) Plant functional traits and environmental filters at a regional scale. J Veg Sci 9:113-122

Diaz S, Purvis A, Cornelissen JHC, Mace GM, Donogue MJ, Ewers RM, Jordano P, Pearse WD (2013) Functional traits, the phylogeny of function, and ecosystem service vulnerability. Ecol Evol. 3:2958-2957

Dorrepaal E, Aerts R, Cornelissen JHC, Callaghan TV, van Logtestijn RSP (2004) Summer warming and increased winter snow cover affect Sphagnum fuscum growth, structure and production in a sub-arctic bog. Glob Change Biol 10:93-104

Elmendorf SC, Henry GHR, Hollister RD, Björk RG, BoulangerLapointe N, Cooper EJ et al (2012) Plot-scale evidence of tundra vegetation change and links to recent summer warming. Nat Clim Change 2:453-457

Elumeeva EG, Soudzilovskaia NA, During HJ, Cornelissen JHC (2011) The importance of shoot adaptation versus aggregation for the water balance of subarctic bryophytes. J Veg Sci 122:152-164

Freschet GT, Cornwell WK, Wardle DA, Tatyana GE, Liu W, Jackson BG, Onipchenko VG, Soudzilovskaia NA, Tao J, Cornelissen JHC (2013) Linking litter decomposition of aboveand below-ground organs to plant-soil feedbacks worldwide. J Ecol 101:943-952

Gavazov KS, Soudzilovskaia NA, van Logtestijn RSP, Braster M, Cornelissen JHC (2010) Isotopic analysis of cyanobacterial nitrogen fixation associated with subarctic lichen and bryophyte species. Plant Soil 333:507-517

Gorham E (1991) Northern peatlands: role in the carbon cycle and probable responses to climatic warming. Ecol Appl 1:182-195

Gornall JL, Jonsdottir IS, Woodin SJ, Van der Wall R (2007) Arctic mosses govern below-ground environment and ecosystem processes. Oecologia 153:931-941

Grime JP (1998) Benefits of plant diversity to ecosystems: immediate, filter and founder effects. J Ecol 86:902-910

Hacke U, Sperry JS, Feild T, Sano Y, Sikkema E, Pittermann J (2007) Water transport in vessel-less angiosperms: conducting efficiency and cavitation safety. Int J Plant Sci 168:1113-1126

Hattenschwiler S, Vitousek PM (2000) The role of polyphenols in terrestrial ecosystem nutrient cycling. Trends Ecol Evol 15:238-243

Hekneby, M. Antolín C, Sánchez-Díaz M (2006) Frost resistance and biochemical changes during cold acclimation in different annual legumes. Environ Exp Bot 55:305-314

Hobbie SE, Chapin FS III (1996) Winter regulation of tundra litter carbon and nitrogen dynamics. Biogeochemistry 35:327-338

Ibanez S, Lavorel S, Puijalon S, Moretti M (2013) Herbivory mediated by coupling between biomechanical traits of plants and grasshoppers. Funct Ecol. 2:479-489
Insarova G, Insarova I (1996) Assessment of lichen sensitivity to climate change. Isr J Plant Sci 44:309-334

IPCC (2007) Climate change 2007: the physical science basis. Contribution of Working Group I to the Fourth Assessment Report of the Intergovernmental Panel on Climate Change. Cambridge University Press, Cambridge

Johansson C, Pohjola VA, Jonasson C, Callaghan TV (2011) Multi-decadal changes in snow characteristics in sub-arctic Sweden. Ambio 40:566-574

Jonas T, Rixen C, Sturm M, Stoeckli V (2008) How alpine plant growth is linked to snow cover and climate variability. J Geophys Res B 113:G03013

Jonasson S, Callaghan TV (1992) Root mechanical-properties related to disturbed and stressed habitats in the arctic. New Phytol 122:179-186

Jonasson S, Sköld SE (1983) Influence of frost-heaving on vegetation and nutrient regime of polygon-patterned ground. Vegetatio 53:97-112

Kappen L (1993) Plant activity under snow and ice, with particular reference to lichens. Arctic 46:297-302

Kappen L (2000) Some aspects of the great success of lichens in Antarctica. Antarct Sci 12:314-324

Kappen L, Sommerkorn M, Schroeter B (1995) Carbon acquisition and water relations of lichens in polar regions - potentials and limitations. Lichenologist 27:531-545

Kasuga J, Arakawa K, Fujikawa S (2007) High accumulation of soluble sugars in deep supercooling Japanese white birch xylem parenchyma cells. New Phytol 174:569-579

Kasuga J, Hashidoko Y, Nishioka A, Yoshiba M, Arakawa K, Fujikawa S (2008) Deep supercooling xylem parenchyma cells of katsura tree (Cercidiphyllum japonicum) contain flavonol glycosides exhibiting high anti-ice nucleation activity. Plant Cell Environ 31:1335-1348

Kawai Y, Kudo G (2011) Local differentiation of flowering phenology in an alpine-snowbed herb Gentiana nipponica. Botany 89:361-367

Keuper F, Dorrepaal E, van Bodegom PM, Aerts R, van Logtestijn RSP, Callaghan TV, Cornelissen JHC (2011) A race for space? How Sphagnum fuscum stabilizes vegetation composition during long-term climate manipulations. Glob Change Biol $17: 2162-2171$

Körner Ch (2003) Alpine plant life, 2nd edn. Springer, Heidelberg

Krab EJ (2013) What's up down there - climate change effects on subarctic springtail communities and their role in carbon turnover. $\mathrm{PhD}$ thesis, VU University, Amsterdam

Kreyling J, Jurasinski G, Grant K, Retzer V, Jentsch A, Belerkuhnlein C (2011) Winter warming pulses affect the development of planted temperate grassland and dwarf-shrub heath communities. Plant Ecol Div 4:13-21

Kreyling J, Haei M, Laudon H (2012) Absence of snow cover reduces understory plant cover and alters plant community composition in boreal forests. Oecologia 168:577-587

Kudo G, Nordenhall U, Molau U (1999) Effects of snow-melt timing on leaf traits, leaf production and shoot growth of alpine plants: comparisons along a snow-melt gradient in northern Sweden. Ecoscience 6:439-450

Ladinig U, Hacker J, Neuner G, Wagner J (2013) How endangered is sexual reproduction of high-mountain plants by summer frosts? Frost resistance, frequency of frost events and risk assessment. Oecologia 171:743-760

Lang SI, Cornelissen JHC, Klahn T, van Logtestijn RSP, Broekman R, Schweikert W, Aerts R (2009) An experimental comparison of chemical traits and litter decomposition rates in a diverse range of subarctic bryophyte, lichen and vascular plant species. J Ecol 97:886-900

Lavorel S, Garnier E (2002) Predicting changes in community composition and ecosystem functioning from plant traits: revisiting the Holy Grail. Funct Ecol 16:545-556

Longton RE (1997) The role of bryophytes and lichens in polar ecosystems. In: Woodin SJ, Marquiss M (eds) Ecology of arctic environments. Blackwell Science Ltd, Oxford, pp 69-96 
Makoto M, Klaminder J (2012) The influence of non-sorted circles on species diversity of vascular plants, bryophytes and lichens in sub-arctic tundra. Polar Biol 35:1659-1667

Makoto K, Kajimoto T, Koyama L, Kudo G, Shibata H, Yanai Y, Cornelissen JHC (2013) Winter climate change in plant-soil system: summary of recent findings and future perspectives. Ecol Res. doi:10.1007/s11284-013-1115-0

Mårell A, Hofgaard A, Danell K (2006) Nutrient dynamics of reindeer forage species along snowmelt gradients at different ecological scales. Basic Appl Ecol 7:13-30

Michel P, Lee WG, During HJ, Cornelissen JHC (2012) Species traits and their non-additive interactions control the water economy of bryophyte cushions. J Ecol 100:222-231

Nash TH III (1996) Nitrogen, its metabolism and potential contribution to ecosystems. In: Nash TH III (ed) Lichen biology. Cambridge University Press, Cambridge, pp 121-135

Onipchenko VG, Makarov MI, van Logtestijn RSP, Ivanov VB, Akhmetzanova AA, Tekeev DK, Ermak AA, Salpagarova FS, Kozhevnikova AD, Cornelissen JHC (2009) New nitrogen uptake strategy: specialized snow roots. Ecol Lett 12:758-764

Onipchenko VG, Makarov MI, Akhmetzhanova AA, Soudzilovskaia NA, Aibazova FU, Elkanova MK, Stogova AV, Cornelissen JHC (2012) Alpine plant functional group responses to fertiliser addition depend on abiotic regime and community composition. Plant Soil 357:103-115

Onipchenko VG, Kipkeev A, Makarov MI, Kozhevnikova A, Ivanov V, Soudzilovskaia NA, Tekeev D, Salpagarova F, Werger MJA, Cornelissen JHC (2013) Digging deep to open the white black box of snow root phenology. Ecol Res. doi: $10.1007 / \mathrm{s} 11284-013-1112-3$

Palmqvist K (1995) Uptake and fixation of $\mathrm{CO}_{2}$ in lichen symbionts. Symbiosis 18:95-109

Pérez-Harguindeguy N, Díaz S, Garnier E, Lavorel S, Poorter H, Wright IJ, Yay P, Enrico L, Pausas JG, de Vos AC, Buchmann N, Funes G, Quétier F, Hodgson JG, Thompson K, Morgan HD, ter Steege H, van der Heijden MGA, Sack L, Blonder B, Poschlod P, Vaieretti MV, Conti G, Staver AC, Aquino S, Cornelissen JHC (2013) New handbook for standardised measurement of plant functional traits worldwide. Aust J Bot 61:167-234

Quetier F, Lavorel S, Thuiller W, Davies I (2007) Plant-trait-based modeling assessment of ecosystem-service sensitivity to land-use change. Ecol Appl 17:2377-2386

Rogers MC, Sullivan PF, Welker JM (2011) Evidence of nonlinearity in the response of net ecosystem $\mathrm{CO}_{2}$ exchange to increasing levels of winter snow depth in the high arctic of northwest Greenland. Arct Antarct Alp Res 43:95-106

Schimel JP, Bilbrough C, Welker JA (2004) Increased snow depth affects microbial activity and nitrogen mineralization in two Arctic tundra communities. Soil Biol Biochem 36:217-227
Soudzilovskaia NA, van Bodegom PM, Cornelissen JHC (2013) Dominant bryophyte control over high-latitude soil temperature fluctuations predicted by heat transfer traits, field moisture regime and laws of thermal insulation. Funct Ecol 27:1442-1454

Starr G, Oberbauer SF, Pop EW (2000) Effects of lengthened growing season and soil warming on the phenology and physiology of Polygonum bistorta. Glob Change Biol 6:357-369

Street LE, Subk JA, Sommerkorn M, Sloan V, Ducrotoy H, Phoenix GK, Williams M (2013) The role of mosses in carbon uptake and partitioning in arctic vegetation. New Phytol 199:163-175

Sturm M, Schimel J, Michaelson G, Welker JM, Oberbauer SF, Liston GE, Fahnestock J, Romanovsky VE (2005) Winter biological processes could help convert arctic tundra to shrubland. Bioscience 55:17-26

Suding KN, Lavorel S, Chapin FS III, Cornelissen JHC, Díaz S, Garnier E, Goldberg D, Hooper D, Jackson ST, Navas M-L (2008) Scaling environmental change from traits to communities to ecosystems: the challenge of complexity at intermediate scales. Glob Change Biol 14:1-16

Torp M, Olofsson J, Witzell J, Baxter R (2010) Snow-induced changes in dwarf birch chemistry increase moth larval growth rate and level of herbivory. Polar Biol 33:693-702

Violle C, Navas M-L, Vile D, Kazzakou E, Fortunel C, Hummel I, Garnier E (2007) Let the concept of trait be functional! Oikos 116:882-892

Wahren CHA, Walker MD, Bret-Harte MS (2005) Vegetation responses in Alaskan arctic tundra after 8 years of a summer warming and winter snow manipulation experiment. Glob Change Biol 11:537-552

Walsh NE, McCabe TR, Welker JM, Parsons AN (1997) Experimental manipulations of snow-depth: effects on nutrient content of caribou forage. Glob Change Biol 3:158-164

Wang X, Arora R, Horner HT, Krebs SL (2008) Structural adaptations in overwintering leaves of thermonastic and nonthermonastic Rhododendron species. J Am Soc Hortic Sci 133:768-776

Wipf S, Rixen C (2010) A review of snow manipulation experiments in arctic and alpine tundra ecosystems. Polar Res 29:95-109

Wipf S, Stoeckli V, Bebi P (2009) Winter climate change in alpine tundra: plant responses to changes in snow depth and snowmelt timing. Clim Change 94:105-121

Wookey PA, Aerts R, Bardgett RD, Baptist F, Bråthen KA, Cornelissen JHC, Gough L, Hartley I, Hopkins D, Lavorel S, Shaver GR (2009) Ecosystem feedbacks and cascade processes: understanding their role in the responses of arctic and alpine ecosystems to environmental change. Glob Change Biol 15:1153-1172

Wu F, Yang W, Zhang J, Deng R (2010) Litter decomposition in two subalpine forests during the freeze-thaw season. Acta Oecologica 36:135-140 